OPEN ACCESS

Edited by: Robert G. Franks, North Carolina State University, USA

Reviewed by:

Michael Lenhard,

University of Potsdam, Germany

Miguel Angel Flores-Vergara, North Carolina State University, USA

*Correspondence:

Dun Y. Tan

tandunyan@163.com

Specialty section:

This article was submitted to Plant Evolution and Development, a section of the journal

Frontiers in Plant Science

Received: 01 November 2016 Accepted: 24 January 2017

Published: 09 February 2017

Citation:

Lu JJ, Tan DY, Baskin CC and Baskin JM (2017) Effect of Seed

Position on Parental Plant on Proportion of Seeds Produced with Nondeep and Intermediate

Physiological Dormancy.

Front. Plant Sci. 8:147.

doi: 10.3389/fpls.2017.00147

\section{Effect of Seed Position on Parental Plant on Proportion of Seeds Produced with Nondeep and Intermediate Physiological Dormancy}

\author{
Juan J. Lu', Dun Y. Tan ${ }^{1 *}$, Carol C. Baskin ${ }^{1,2,3}$ and Jerry M. Baskin ${ }^{1,2}$ \\ ${ }^{1}$ College of Grassland and Environment Sciences, Xinjiang Agricultural University, Urümqi, China, ${ }^{2}$ Department of Biology, \\ University of Kentucky, Lexington, KY, USA, ${ }^{3}$ Department of Plant and Soil Sciences, University of Kentucky, Lexington, $K Y$, \\ USA
}

The position in which seeds develop on the parental plant can have an effect on dormancy-break and germination. We tested the hypothesis that the proportion of seeds with intermediate physiological dormancy (PD) produced in the proximal position on a raceme of Isatis violascens plants is higher than that produced in the distal position, and further that this difference is related to temperature during seed development. Plants were watered at 3-day intervals, and silicles and seeds from the proximal (early) and distal (late) positions of racemes on the same plants were collected separately and tested for germination. After 0 and 6 months dry storage at room temperature (afterripening), silicles and seeds were cold stratified for 0-16 weeks and tested for germination. Mean daily maximum and minimum temperatures during development/maturation of the two groups of seeds did not differ. A higher proportion of seeds with the intermediate level than with the nondeep level of PD was produced by silicles in the proximal position than by those in the distal position, while the proportion of seeds with nondeep PD was higher in the distal than in the proximal position of the raceme. The differences were not due only to seed mass. Since temperature and soil moisture conditions were the same during development of the seeds in the raceme, differences in proportion of seeds with intermediate and nondeep PD are attributed to position on parental plant. The ecological consequence of this phenomenon is that it ensures diversity in dormancy-breaking and germination characteristics within a seed cohort, a probable bet-hedging strategy. This is the first demonstration of position effects on level of PD in the offspring.

Keywords: Brassicaceae, cold stratification, Isatis violascens, seed dormancy, silicles

\section{INTRODUCTION}

According to the Nikolaeva-Baskin classification system, there are five classes of seed dormancy, i.e., physiological dormancy (PD), morphological dormancy (MD), morphophysiological dormancy (MPD), physical dormancy (PY), and combinational dormancy (PY + PD) (Baskin and Baskin, 2014). PD is caused by low growth potential of the embryo, and it occurs in three increasing 
degrees or depths (intensities) of dormancy as follows: nondeep $\mathrm{PD}<$ intermediate PD < deep PD. Nondeep PD can be broken by high $\left(\geq 15^{\circ} \mathrm{C}\right)$ or low $\left(0-10^{\circ} \mathrm{C}\right.$ and wet, i.e., cold stratification $)$ temperatures, depending on the species, and it is the most common kind of seed dormancy on Earth. In temperate regions of the world, intermediate and deep PD can be broken by long periods of cold stratification. However, exposure of seeds with intermediate PD to high temperatures for 2-3 months before the beginning of cold stratification significantly decreases the length of the cold treatment required to break dormancy (Baskin and Baskin, 2014).

Seeds produced under different temperature conditions can vary in intensity of PD. Generally, seeds produced at high temperatures are less dormant than those produced at low temperatures (Baskin and Baskin, 2014), but there are a few exceptions for which the reverse is true (Koller, 1962; Groves et al., 1982). Seeds of some species, including those of Thlaspi arvense (Brassicaceae) (Hume, 1994), collected in the early part of the growing season when temperatures are relatively low, are more dormant than those collected late in the growing season when temperature are relatively high (Baskin and Baskin, 2014, p. 326). However, germination percentage of early- and latecollected seeds of Brassica campestris was the same (Singh et al., 1976).

In a seed cohort of Isatis violascens Bunge (Brassicaceae), there are two levels of PD: nondeep and intermediate (Zhou et al., 2015). Seeds with nondeep PD afterripen (come out of dormancy) during summer and germinate in autumn if the soil is moist; otherwise, germination is delayed until next spring. Seeds with intermediate $\mathrm{PD}$ require $\geq 12$ weeks of cold stratification for dormancy break; however, a period of dry storage (afterripening) significantly decreases the length of the cold stratification period required to break dormancy. In the field, seeds with intermediate PD afterripen in summer, are cold stratified in winter and germinate in spring. Seeds with nondeep PD can germinate in autumn or spring, while those with intermediate PD can germinate only in spring (Lu et al., 2016). In a seed cohort of I. violascens collected in 2013, 20-25\% of the seeds had nondeep PD and 75-80\% intermediate PD (Zhou et al., 2015).

Timing and position of seed development on the parental plant can affect the intensity of PD (Hume, 1994; Baskin and Baskin, 2014). Thus, we hypothesized that plants of I. violascens produce seeds with intermediate $\mathrm{PD}$ under relatively cool conditions in early spring (proximal position on raceme) and seeds with nondeep PD under relatively warm conditions in mid to late spring (distal position on raceme). To address this hypothesis, we asked: does the proportion of nondeep and intermediate $\mathrm{PD}$ differ, depending on time, position and/or temperature during seed development/maturation.

Isatis violascens is an annual, native to central Asia, and in China it grows on sand dunes in the Garbantunggut Desert of Xinjiang (Zhou et al., 2011). Indehiscent intact silicles are the dispersal and germination units of this species (Liu and Tan, 2007). Each silicle has a membranous wing around it and contains a single seed. Each plant produces one to five racemes with a total of 15-200 silicles, depending on size of the plant (Zhou et al., 2015). Thus, early produced silicles/seeds were collected from a large number of plants, and late-produced silicles/seeds subsequently were collected from the same plants.

\section{MATERIALS AND METHODS}

\section{Silicle Production and Description}

In early June 2013, dispersal units (i.e., silicles) were collected from about 1000 plants growing in a natural population of I. violascens on a cold desert sand dune in Fukang City in the southern part of the Junggar Basin of Xinjiang Province $\left(44^{\circ} 22^{\prime} \mathrm{N}, 88^{\circ} 08^{\prime} \mathrm{E}, 458 \mathrm{~m}\right.$ a.s.l.), China. Approximately 10,000 silicles were sown in an experimental garden on the campus of Xinjiang Agricultural University in Urümqi, on the southern edge of the Junggar Basin $\left(43^{\circ} 53^{\prime} \mathrm{N}, 87^{\circ} 33^{\prime} \mathrm{E}, 696 \mathrm{~m}\right.$ a.s.l.). This population has regenerated each year after sowing, and in 2015, when silicles were collected for this study, it contained about 1000 plants.

During the 2015 germination and plant growth season (i.e., 18 March to 10 June for I. violascens), the soil was watered to field capacity every 3 days to ensure that water was not a limiting factor for seed germination, seedling survival, prereproductive growth and seed production and development. During seed development, approximately 800 plants were selected for collection of mature silicles. The first green silicle from the proximal position on 2-5 racemes on each of the 800 plants was marked with red nail polish on 1 May 2015. Fourteen days later (15 May 2015), the first green silicle from the distal position on the same racemes on the same plants was marked with blue nail polish. Each of the two groups of silicles was marked 6-7 days after pollination. Before dispersal, we collected the mature silicles from the proximal (early maturation) and the distal (late-maturation) positions on racemes on 28 May (i.e., 34 days after pollination) and 10 June 2015 (i.e., 34 days after pollination), respectively. The two groups of silicles were stored in separate paper bags at room conditions $\left(16-30^{\circ} \mathrm{C}, 10-40 \%\right.$ $\mathrm{RH}$ ) until used. Mean maximum and minimum air temperatures from seed germination to fruit maturity (i.e., March to June 2015) are shown in Figure 1 (National Meteorological Information Center, China Meteorological Administration, http://cdc.nmic. $\mathrm{cn} /)$.

\section{Mass of Silicle, Seed, Pericarp, Embryo, and Seed Coat}

Five replications of five intact silicles, of five seeds, of pericarps from five silicles, of five embryos and of seed coats from five seeds from distal and proximal positions on racemes were weighed individually using a Sartorius BS210S electronic-balance (0.0001 g).

\section{Presence of Nondeep PD}

By conducting tests for nondeep and intermediate PD in seeds from both distal and proximal positions on the racemes, we can determine if the proportion of nondeep and intermediate PD differs for seeds matured at different times and positions. If seeds 


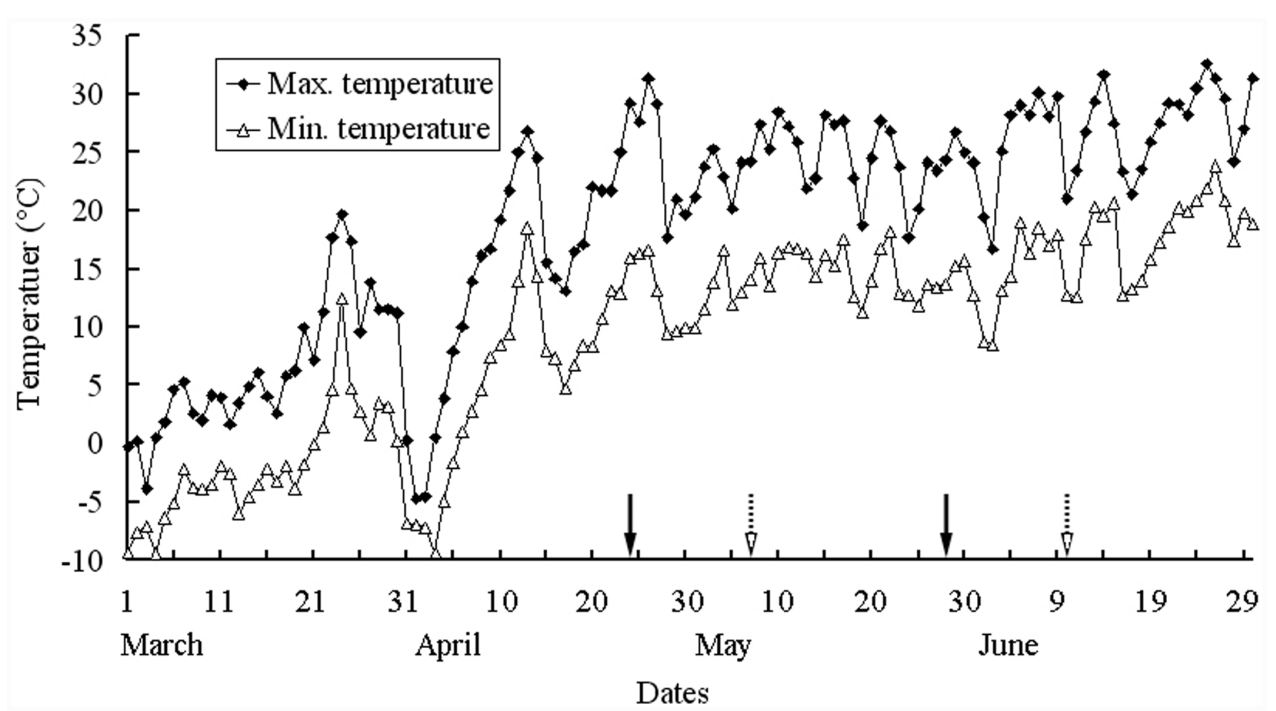

FIGURE 1 | Mean maximum and minimum temperatures from March to June $\mathbf{2 0 1 5}$ in Urümqi, China. Arrows with solid and broken lines are the periods from flowering to silicle maturation for proximal and distal positions on racemes of Isatis violascens, respectively. The weather data were provided by Geographical Information Monitoring Cloud Platform.

of I. violascens have nondeep PD, they will afterripen during dry storage at room temperature (Zhou et al., 2015). After silicles from distal and proximal positions on racemes had been stored dry in the laboratory for 0 (i.e., June 2015) and 6 months (i.e., December 2015), intact silicles and isolated seeds from distal and proximal positions on racemes were incubated in Petri dishes on wet filter paper at $5 / 2^{\circ} \mathrm{C}$ in darkness, the optimum conditions for germination (Zhou et al., 2015). Four replicates of 25 intact silicles and of 25 isolated seeds each from distal and proximal positions on racemes were used to test germination. Silicles and seeds were checked only after 28 days; therefore, they were not exposed to any light during the incubation period.

After the germination trials were complete, the nongerminated seeds were tested for viability. Seeds were cut open and the embryo observed. Seeds with white, firm embryos were counted as viable, and those with tan, soft embryos were considered nonviable and excluded from the calculations of germination percentages. Only a very few seeds were non-viable. The tests of fresh seeds ( 0 month old) from distal and proximal positions on racemes were initiated on 31 May and 12 June 2015, respectively, using seeds collected on 28 May and 10 June 2015, respectively.

\section{Presence of Intermediate PD}

Seeds of $I$. violascens with intermediate PD will germinate after they have been dry stored (afterripened) for 6 months and then given a cold stratification treatment (Zhou et al., 2015). To determine the proportion of seeds from distal and proximal positions on racemes that had intermediate $\mathrm{PD}$, we used seeds and silicles from these two positions that had been stored dry at room temperature for 6 months. Six-month-old intact silicles and isolated seeds from distal and proximal positions on racemes were cold stratified on moist filter paper at $4^{\circ} \mathrm{C}$ for $0,4,8,12$, and
16 weeks. After each period of cold stratification, four replications of 25 silicles and of 25 seeds from both positions were checked for germination. Then, four replicates of 25 intact silicles and of 25 isolated seeds from both positions that did not germinate after each period of cold stratification were tested for germination at $5 / 2^{\circ} \mathrm{C}$ in darkness for 28 days. Since $>90 \%$ of intact silicles and of isolated seeds germinated during the 16 weeks of cold stratification, no germination test per se was performed.

\section{Statistical Analysis}

Independent-sample $t$-test were used to compare the differences in silicle, seed, pericarp, embryo, and seed coat mass between distal and proximal positions on racemes. Germination data were analyzed using generalized linear models (GLMs) with a logit link to germination as a binomial response variable (two categories: germinated versus non-germinated). In the models, silicle position (distal and proximal positions on racemes), treatment (intact silicles and isolated seeds) and storage time (0 and 6 months) were used as fixed factors for the "Presence of nondeep PD" experiment, and silicle positions (distal and proximal positions on racemes), treatment and cold stratification time $(0,4,8$, and 12 weeks $)$ were used as fixed factors for the "Presence of intermediate PD" experiment, with their interactions included in the models. The significance of effects of fixed factors and their interactions in the models was tested by Wald $\chi^{2}$ values. Tukey's HSD test was performed for multiple comparisons to determine significant differences among treatments. Correlative analyses were used to determine the relationship between embryo mass and germination percentage of 6-month-old dry-stored seeds from distal and proximal positions on racemes. With mass of seeds as a covariate, a oneway ANCOVA was used to determine whether the proportion of seeds with intermediate and nondeep PD differed between 
seeds produced in the distal and proximal position of the raceme. Statistical tests were conducted at $P=0.05$. All data analyses were performed with the software SPSS 16.0 (SPSS, Inc., Chicago, IL, USA). Values are mean \pm 1 SE (i.e., standard errors).

\section{RESULTS}

\section{Mass of Silicle, Seed, Pericarp, Embryo, and Seed Coat}

Mass of whole silicles, whole seeds, and embryos from the proximal position on the raceme was significantly greater than that of silicles, seeds, and embryos from the distal position However, there was no significant difference in mass of pericarps or seed coats between these two positions on raceme (Table 1).

\section{Presence of Nondeep PD}

Generalized linear models analysis showed that germination was significantly affected by silicle position on raceme and storage time; however, the effect of treatment (i.e., intact silicles and isolated seeds) and of the various interactions was not significant (Table 2). At storage time zero, germination of seeds in intact silicles and isolated seeds from distal and proximal positions on the racemes was 1-8\% (Figure 2). After 6 months of dry storage, 24 and $30 \%$ of seeds in silicles and isolated seeds from the distal position on the racemes germinated, respectively, but only 6 and $10 \%$ of those from the proximal position on the racemes germinated, respectively (Figure 2).

\section{Presence of Intermediate PD}

Generalized linear models analysis showed that the effects of silicle position on raceme, treatment (i.e., intact silicles and isolated seeds) and cold stratification time on germination were highly significant, but none of the interactions had significant effects (Table 2). With increase in cold stratification time, germination of seeds in silicles and isolated seeds from distal and proximal positions on the racemes increased significantly, and they germinated to $93-96 \%$ during 16 weeks at $4^{\circ} \mathrm{C}$ (Figure 3A). After 12 weeks of cold stratification at $4^{\circ} \mathrm{C}$, at time of transfer to $5 / 2^{\circ} \mathrm{C}$, germination of seeds in silicles and isolated seeds from the distal position of the racemes was 83 and $87 \%$, respectively, and that of seeds in silicles and isolated seeds from the proximal

TABLE 1 | Effects of silicle position on silicle, seed, pericarp, embryo, and seed coat mass in Isatis violascens ( $\mathrm{mg}$, mean of five individuals $\pm 1 \mathrm{SE}$ ).

\begin{tabular}{lcc}
\hline & DR & PR \\
\hline Silicle & $37.66 \pm 0.59^{\mathrm{a}}$ & $42.00 \pm 0.34^{\mathrm{b}}$ \\
Seed & $18.90 \pm 0.36^{\mathrm{a}}$ & $22.82 \pm 0.15^{\mathrm{b}}$ \\
Pericarp & $18.76 \pm 0.23^{\mathrm{a}}$ & $19.18 \pm 0.38^{\mathrm{a}}$ \\
Embryo & $17.9 \pm 0.10^{\mathrm{a}}$ & $21.86 \pm 0.43^{\mathrm{b}}$ \\
Seed coat & $1.76 \pm 0.12^{\mathrm{a}}$ & $2.32 \pm 0.29^{\mathrm{a}}$ \\
\hline
\end{tabular}

$D R$, distal position on raceme; $P R$, proximal position on raceme. Different lowercase letters in a row indicate significant differences $(P<0.05)$ between $D R$ and $P R$ by t-test.
TABLE 2 | Generalized linear models of effects of silicle position on raceme $(P)$, treatment $(T)$, storage time $(S)$, and their interactions on presence of nondeep PD and of silicle position on raceme (P), treatment (T), cold stratification time (C), and their interactions on presence of intermediate PD in Isatis violascens.

\begin{tabular}{|c|c|c|c|}
\hline Factor & d.f. & Wald- $\chi^{2}$ & $P$-value \\
\hline \multicolumn{4}{|c|}{ Presence of nondeep PD } \\
\hline$P$ & 1 & 18.652 & $<0.05$ \\
\hline $\mathrm{T}$ & 1 & 1.325 & 0.250 \\
\hline S & 1 & 19.598 & $<0.05$ \\
\hline$P \times T$ & 1 & 0.297 & 0.586 \\
\hline$P \times S$ & 1 & 0.118 & 0.731 \\
\hline $\mathrm{T} \times \mathrm{S}$ & 1 & 0.000 & 0.994 \\
\hline$P \times T \times S$ & 1 & 0.044 & 0.834 \\
\hline \multicolumn{4}{|c|}{ Presence of intermediate PD } \\
\hline$P$ & 1 & 167.519 & $<0.05$ \\
\hline $\mathrm{T}$ & 1 & 5.508 & $<0.05$ \\
\hline C & 3 & 178.883 & $<0.05$ \\
\hline$P \times T$ & 1 & 0.027 & 0.868 \\
\hline$P \times C$ & 3 & 1.643 & 0.650 \\
\hline $\mathrm{T} \times \mathrm{C}$ & 3 & 0.424 & 0.935 \\
\hline$P \times T \times C$ & 3 & 0.232 & 0.972 \\
\hline
\end{tabular}

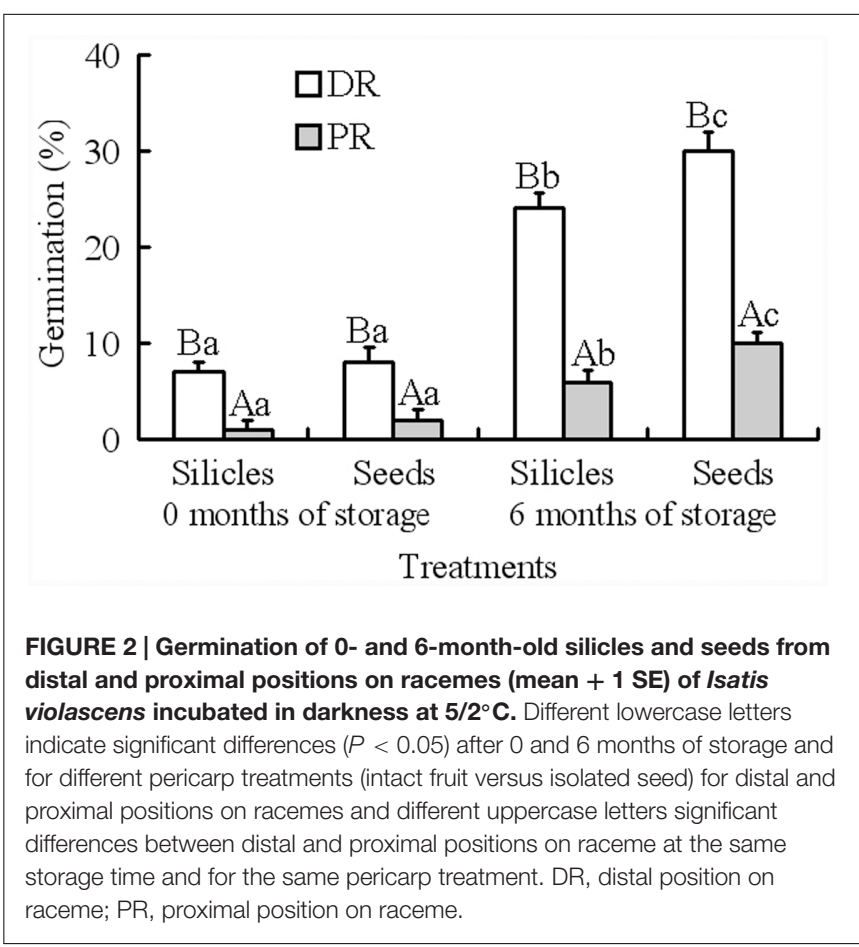

position of racemes was 43 and 51\%, respectively (Figure 3B). However, after 16 weeks of cold stratification at $4^{\circ} \mathrm{C},>90 \%$ of the seeds from both positions had germinated (Figure 3A); thus, a germination test was not performed.

Additionally, the results of correlative analyses showed that there was a significantly negative relationship between embryo mass and germination percentage of 6-month-old drystored seeds from distal positions on racemes $(r=-0.948$, 

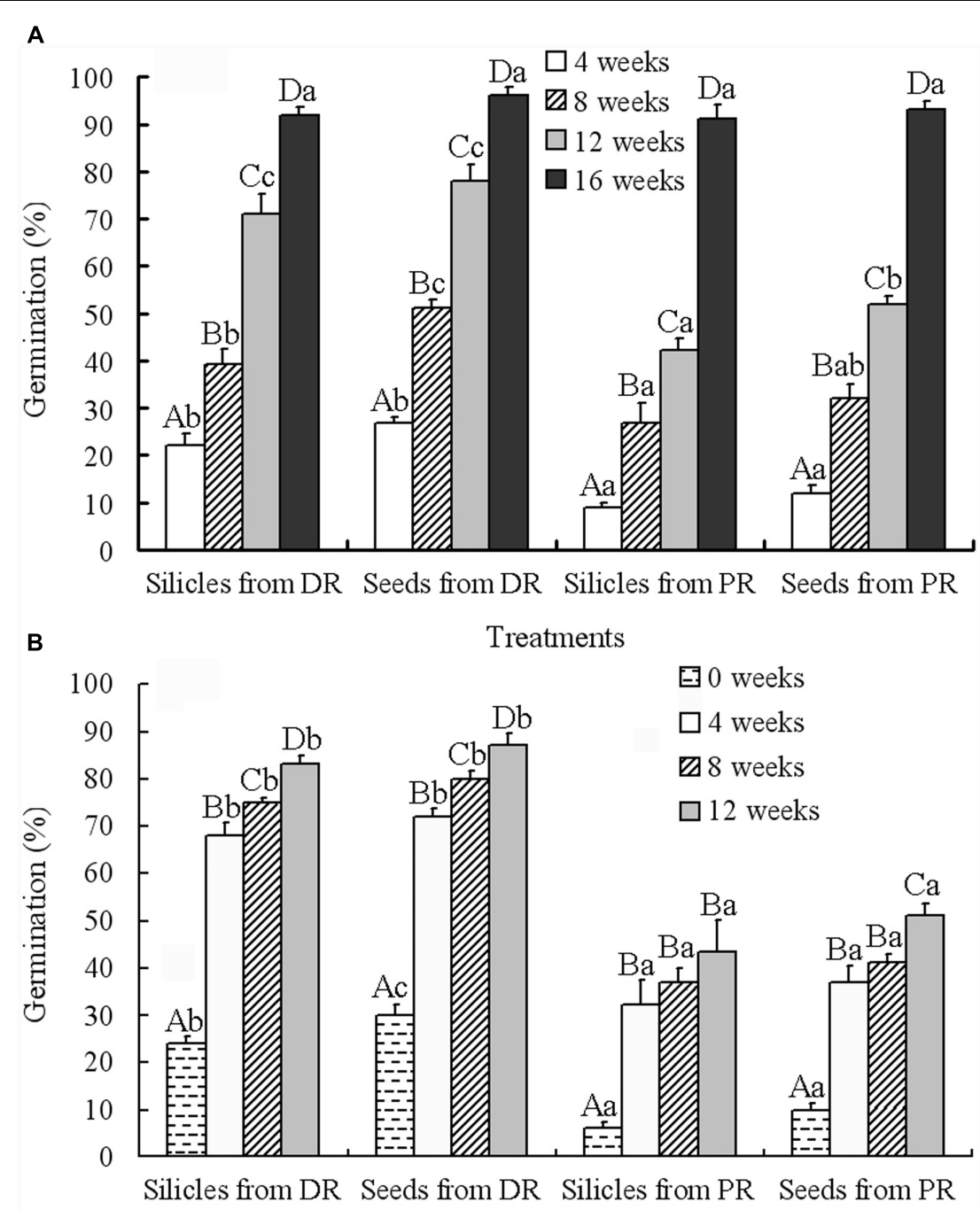

Treatments

FIGURE 3 | Effect of cold stratification on germination (mean $+1 \mathrm{SE}$ ) of 6-month-old dry-stored silicles and seeds from distal and proximal positions on racemes of Isatis violascens during cold stratification at $4^{\circ} \mathbf{C}$ for $\mathbf{4 , 8 , 1 2}$, and $\mathbf{1 6}$ weeks $(\mathbf{A})$ and during incubation at $5 / 2^{\circ} \mathrm{C}$ in darkness after cold stratification for 0, 4, 8, and 12 weeks (B). Different uppercase letters indicate significant differences $(P<0.05)$ among different treatments at the same cold stratification time and different lowercase letters significant differences among different cold stratification times within the same treatment. DR, distal position on raceme; PR, proximal position on raceme.

$P<0.001$ ), but a positive relationship between embryo mass and germination percentage of 6-month-old dry-stored seeds from proximal positions $(r=0.948, P<0.001)$. Also, a one-way ANCOVA indicated a significant effect of seed position on the raceme on proportion of seeds with intermediate and nondeep $\mathrm{PD}(P<0.05)$.

\section{DISCUSSION}

Our hypothesis that plants of $I$. violascens produce seeds with intermediate PD in early spring and seeds with nondeep PD in mid- to late spring was supported in part. That is, while the proportion of seeds with intermediate $\mathrm{PD}$ was higher in the proximal (early) part of the raceme (90\%) than in the distal (late) part $(70 \%)$, some seeds with nondeep PD (10\%) were produced in the proximal position. Also, while the proportion of seeds with nondeep PD was higher in the distal (30\%) than proximal (10\%) position of the raceme, seeds with intermediate PD (70\%) also were produced in the distal position (Figures 2 and 3B). Thus, seeds with nondeep and intermediate PD are produced in both the proximal and distal positions of the raceme, but the proportion of seeds with the two levels of $\mathrm{PD}$ varies between the two positions.

During the 34-day period from flowering to maturation of seeds in both the distal and proximal positions of the raceme, plants were well watered, and mean daily maximum and minimum temperatures were $24.4 / 14.1$ and $24.9 / 14.7^{\circ} \mathrm{C}$, 
respectively, for the two periods of development. Thus, discounting the relatively small differences in day length and photon irradiance during the two periods of maturation, growth conditions of the plants while seeds developed in the two positions on the racemes were the same. It should be noted that 22 days of the two periods of maturation overlapped with each other (Figure 1). Thus, the major difference between seeds produced in the proximal and distal positions on the raceme was position per se on the mother plant.

Various studies have been conducted on the effects of the position of diaspore monomorphic fruit/seeds on the mother plant on seed mass and germination (Baskin and Baskin, 2014). In considering seeds produced in different parts of the same inflorescence, dormancy of seeds produced in the proximal part of the inflorenscence generally is greater than that of seeds produced in the distal part (e.g., Espadaler and Gomez, 2001; Wang et al., 2010). Thus, the higher proportion of intermediate than of nondeep PD in the proximal part of the raceme of $I$. violascens is consistent with results reported in the literature. In Oldenlandia corymbosa, however, seeds produced along the main axis of the inflorescence and at proximal ends of inflorescence branches were more dormant than these produced at distal ends of inflorescence branches (Do Cao et al., 1978).

Another consequence of position in the inflorescence is that proximal seeds often have greater mass than distal ones, e.g., the Brassicaceae species Alliaria petiolata (Susko and Lovett-Doust, 2000a,b) and Brassica napus (Clarke, 1979). However, seed mass was greater in distal than in proximal parts of the inflorescence of Clarkia unguiculata (Mazer and Dawson, 2001) and did not differ with inflorescence position in Phytolacca rivinoides (Byrne and Mazer, 1990). Since energy resources of the mother plant are limited, it is logical that seeds produced early in the season would have greater mass than those produced late in the season. Indeed, studies on a variety of plant taxa (see Baskin and Baskin, 2014, p. 355), including Alliaria petiolata (Susko and Lovett-Doust, 2000a), have found that seeds from early produced fruits have greater mass than those from late-produced fruits.

The greater dormancy and greater mass of seeds and embryo from the early, proximal position on the I. violascens raceme than from the later, distal position in general are consistent with results reported in the literature for various species, including some other Brassicaceae (Clarke, 1979; Susko and Lovett-Doust, 2000a,b). Even when mass of seeds was considered as a covariant in a one-way ANOVA, there was a significant position effect for a higher proportion of intermediate than nondeep PD for seeds produced in the proximal position of the raceme. This means that the higher proportion of intermediate than nondeep PD on the proximal position of the raceme was not due only to seed mass but to some other factor(s) associated with seed production in this position. What is new about our research is that for the first time we document that two levels of PD in seeds are produced in different positions on the same plants. Specifically, we show that seeds produced in the proximal position of the inflorescence are more likely to have intermediate PD and less likely to have nondeep PD than those on the distal position.
Seeds with intermediate PD produced in the proximal and distal positions on the racemes differed in the amount of cold stratification at $4^{\circ} \mathrm{C}$ required for dormancy break and germination following afterripening for 6 months. Whereas seeds from the distal position on the raceme germinated to $87 \%$ at $5 / 2{ }^{\circ} \mathrm{C}$ after 12 weeks cold stratification at $4^{\circ} \mathrm{C}$, those from the proximal positions germinated to only 51\% (Figure 3B). However, seeds from the proximal position on the raceme had germinated to $96 \%$ after 16 weeks of incubation at $4^{\circ} \mathrm{C}$ (Figure 3B). Thus, 16 weeks of incubation at $4^{\circ} \mathrm{C}$ was more favorable for dormancy break than 12 weeks cold stratification at $4^{\circ} \mathrm{C}$ plus 4 weeks incubation at $5 / 2^{\circ} \mathrm{C}$. The implication of the differences in intermediate $\mathrm{PD}$ between the proximallyand distally- produced seeds is that overall those produced in the proximal position had deeper intermediate PD than those produced late in the season.

\section{CONCLUSION}

The germination/fitness strategy of I. violascens would appear to consist of both a conservative and a diversified bet-hedging strategy (Philippi, 1993): conservative because germination in both autumn and next spring (Zhou et al., 2015) avoids the risk of a complete failure of an autumn-germinating cohort of an annual species that has little potential to form a soil seed bank (Zhou et al., 2015); and diversified because a single plant produces seeds with two levels of PD that can germinate in two different seasons. The production of two levels of PD by plants of $I$. violascens may be one way in which a species that does not produce heteromorphic diaspores that differ in ecology and does not form a persistent seed bank can have a bet-hedging strategy.

\section{AUTHOR CONTRIBUTIONS}

JL and DT conceived and designed the experiments. JL performed the experiments and analyzed the data. JL, DT, CB, and JB wrote the manuscript. All authors reviewed and approved the manuscript.

\section{FUNDING}

This work was supported in part by the National Natural Science Foundation of China (41361011, 31660122), the Major National Scientific Research Program of China (2014CB954202) and the Key Project of Chinese Ministry of Education (213038A).

\section{ACKNOWLEDGMENT}

We thank the National Meteorological Information Center, China Meteorological Administration for providing the weather data. 


\section{REFERENCES}

Baskin, C. C., and Baskin, J. M. (2014). Seeds: Ecology, Biogeography, and Evolution of Dormancy and Germination, 2nd Edn. San Diego, CA: Elsevier/Academic Press.

Byrne, M., and Mazer, S. J. (1990). The effect of position on fruit characteristics, and relationships among components of yield in Phytolacca rivinoides (Phytolaccaceae). Biotropica 22, 353-365. doi: 10.2307/2388553

Clarke, J. M. (1979). Intra-plant variation in number of seeds per pod and seed weight in Brassica napus 'Tower.' Can. J. Plant Sci. 59, 959-962. doi: 10.4141/ cjps79- 152

Do Cao, T., Attims, Y., Corbineau, F., and Come, D. (1978). Germination des graines produites par les plantes de deux lignees d'Oldenlandia corymbosa L. (Rubiacees) cultivees dan des conditions controlees. Physiol. Veg. 16, 521-531.

Espadaler, X., and Gomez, C. (2001). Female performance in Euphorbia characias: effect of flower position on seed quantity and quality. Seed Sci. Res. 11, $163-172$.

Groves, R. H., Hagon, M. W., and Ramakrishnan, P. S. (1982). Dormancy and germination of seed of eight populations of Themeda australis. Aust. J. Bot. 30, 373-386. doi: 10.1071/BT9820373

Hume, L. (1994). Maternal environment effects on plant growth and germination of two strains of Thlaspi arvense L. Int. J. Plant Sci. 155, 180-186. doi: 10.1086/ 297157

Koller, D. (1962). Preconditioning of germination in lettuce at time of fruit ripening. Am. J. Bot. 49, 841-844. doi: 10.2307/2439695

Liu, X. F., and Tan, D. Y. (2007). Diaspore characteristics and dispersal strategies of 24 ephemeral species of Brassicaceae in the Junggar Desert of China. J. Plant Ecol. 31, 1019-1027. doi: 10.17521/cjpe.2007.0129

Lu, J. J., Tan, D. Y., Baskin, C. C., and Baskin, J. M. (2016). Effects of germination season on life history traits and on transgenerational plasticity in seed dormancy in a cold desert annual. Sci. Rep. 6:25076. doi: 10.1038/srep 25076

Mazer, S. J., and Dawson, K. A. (2001). Size-dependent sex allocation within flowers of the annual herb Clarkia unguiculata (Onagraceae): ontogenetic and among-plant variation. Am. J. Bot. 88, 819-831. doi: 10.2307/26 57034
Philippi, T. (1993). Bet-hedging germination of desert annuals: variation among populations and maternal effects in Lepidium lasiocarpum. Am. Nat. 142, 488-507. doi: 10.1086/285551

Singh, V., Singh, C., and Singh, L. R. (1976). Effect of stage of harvesting on yield and seed quality of toria (Brassica campestris var. toria). Seed Res. 4, 108-113.

Susko, D. J., and Lovett-Doust, L. (2000a). Patterns of seed mass variation and their effects on seedlings traits in Alliaria petiolata (Brassicaceae). Am. J. Bot. 87, 56-66. doi: 10.2307/2656685

Susko, D. J., and Lovett-Doust, L. (2000b). Plant-size and fruit-position effects on reproductive allocation in Alliaria petiolata (Brassicaceae). Can. J. Bot. 78, 1398-1407. doi: 10.1139/b00-110

Wang, A. B., Tan, D. Y., Baskin, C. C., and Baskin, J. M. (2010). Effect of seed position in spikelet on life history of Eremopyrum distans (Poaceae) from the cold desert of north-west China. Ann. Bot. 106, 95-105. doi: 10.1093/aob/ mcq089

Zhou, T. Y., Lu, L. L., Yang, G., and Ihsan, A. (2011). "Brassicaceae," in Flora of China, Vol. 8, eds Z. Y. Wu, P. H. Raven, and D. Y. Hong (St. Louis, MO: Missouri Botanical Garden Press).

Zhou, Y. M., Lu, J. J., Tan, D. Y., Baskin, J. M., and Baskin, C. C. (2015). Seed germination ecology of the cold desert annual Isatis violascens (Brassicaceae): two levels of physiological dormancy and role of the pericarp. PLoS ONE 10:e0140983. doi: 10.1371/journal.pone.0140983

Conflict of Interest Statement: The authors declare that the research was conducted in the absence of any commercial or financial relationships that could be construed as a potential conflict of interest.

The reviewer MF-V and handling Editor declared their shared affiliation, and the handling Editor states that the process nevertheless met the standards of a fair and objective review.

Copyright (c) $2017 \mathrm{Lu}$, Tan, Baskin and Baskin. This is an open-access article distributed under the terms of the Creative Commons Attribution License (CC BY). The use, distribution or reproduction in other forums is permitted, provided the original author(s) or licensor are credited and that the original publication in this journal is cited, in accordance with accepted academic practice. No use, distribution or reproduction is permitted which does not comply with these terms. 